\title{
Computer Vision for Screening Resistance Level of Rice Varieties to Brown Planthopper
}

\author{
Elvira Nurfadhilah \\ Department of Computer Science \\ Bogor Agricultural University \\ West Java, Indonesia \\ Yeni Herdiyeni \\ Department of Computer Science \\ Bogor Agricultural University \\ West Java, Indonesia
}

\author{
Aunu Rauf \\ Department of Plant Protection \\ Bogor Agricultural University \\ West Java, Indonesia \\ Rahmini \\ Plant Protection \\ Indonesian Center for Rice Research \\ West Java, Indonesia
}

\begin{abstract}
Brown planthopper is one of the most important insect pest that threatens the stability of national rice production in Indonesia. One of the efforts to save rice production is by using brown planthopper resistant variety. Currently the determination approach is still conventional based on Standard Seedboxes Screening Test from IRRI with assistance of experienced experts in the scoring process resistance level.In this study, a prototype of application system to predict resistance levels by image color approach was developed. The method consists of collecting images data, preparation process (background and objects segmentation), and determination of area proportion which has been infected (sick and dead) and healthy, based on ' $A$ ' value from CIELab color space laboratory. According to proportion value distribution, the rule of rice resistance to brown planthopper assessment based on image was developed. The rule is mostly similar with IRRI standard rules. All of images were assessed based on the rule and then the model was developed with an error rate of $17.02 \%$.
\end{abstract}

Keywords-brown planthopper; color extraction; resistance; standard seedboxes screening test

\section{INTRODUCTION}

Brown planthoppers's latent pestsare difficult to detect, yet their presence had always been a threat to the stability of national rice production.Brown planthopper is a rice-specific herbivore and sucks the phloem sap of rice plants through its stylet mouthpart [1]. Moreover, the brown planthopper attacks may undirectly transfer three lethal viruses for paddy plants, namely the ragged stunt virus,grassy stunt virus type 1 , and grassy stunt virus type 2 . The symptoms of brown planthoppers attack on individual hills of plants include yellowing leaves, followed by drying plants that look burnt / hopperburn[2].

In the effort to save the rice production, many possibilities of pest control are available, including using pest-resistant varieties, natural enemies, cultivation method (planting timing, irrigation, etc), and insecticides [3]. One of the importants aspects of pest control is using planthopper pest-resistant varieties.
The one of the important tasks in overcoming pests is using pest resistant varieties. Indonesian Center for Rice Research is one the centers under the Ministry of Agriculture which focuses on obtaining superior pest-resistant varieties by testing them against various brown planthopper biotypes. Cultivar screening for planthopper resistancy using greenhouse screening used in IRRI is the Standard Seedboxes Screening Test(SSST).

Currently, resistance level using SSST is done manually by experienced experts in resistance level scoring process. Digital image based system prediction is a new approach in screening and scoring the variety resistance level against BPH.

According to Madhogaria [4], the separation between sick and healthy areas can be done by classifying the RGB value using SVM classification. Several experiments have been done to seperate the leaves areas which have been infected with sickness spot with the healthy leaves area, by segmenting the leaves which have been detected sick using the $\mathrm{R}$ component from RGB, A from CIELab, $\mathrm{H}$ from $\mathrm{HSV}$ and $\mathrm{Cr}$ from $\mathrm{YCbCr}$ with Otsu threshold. From the research, the best result was obtained from using the A component from CIELab [5]. Another research [6] has been done to measure the infection severity, by using the component A of CIELab color space on paddy hills images, to differentiate the infected plants from the healthy plants, then looking for the interval through diagram box plot. The measurement accuracy obtained in the experiment was $70.83 \%$.

In this experiment, the ratio of healthy area against the infected area on plant images in seedboxes was calculated using the A component in CIELab color space with multi threshold Otsu. Then classification was done on the damage areas (sick + dead areas) using the interval threshold against the total plant area to classify the ratio of sick areas. The results can be classified into 6 categories, score 0 (Highly Resistant), score 1 (Resistant), score 3 (Moderate Resistant), score 5 (Moderate Susceptible), score 7 (Susceptible) and score 9 (Highly Susceptible). 


\section{MATERIAL AND METHOD}

\section{A. System Framework}

Figure 1 shows the flows of research method. The research method consists of image collection, pre-processing (background and object segmentation), and determination of attack level based on the attacked plant areas.

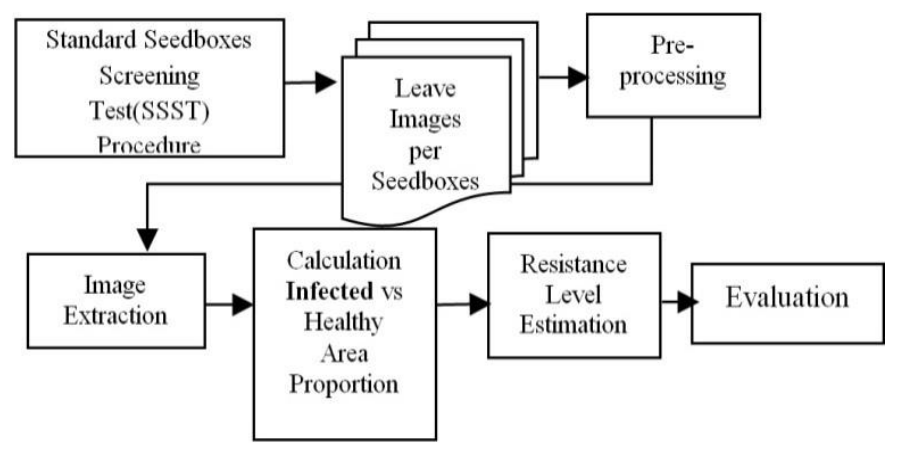

Fig. 1. The System Framework

\section{B. Standard Seedboxes Screening Test (SSST)}

SSST is a method to score the resistance level of each variety against planthoppers by giving several planthopper pairs, then measuring the level of pest growth and its effect on the variety. This method is commonly used to screen the greenhouses in Asia. More than 60,000 entries / year were evaluated in one greenhouse in IRRI. Whereas the procedures to obtain the image data during resistance level scoring using SSST from [6] can be seenin Figure 2 and Table 1.

Table 1 is the standard guidance in manual scoring done in Indonesian Center for Rice Reseach in scoring the paddy plants resistance level against brown planthopper pests, time to scoring when susceptible check(TN1) varieties $90 \%$ dead.

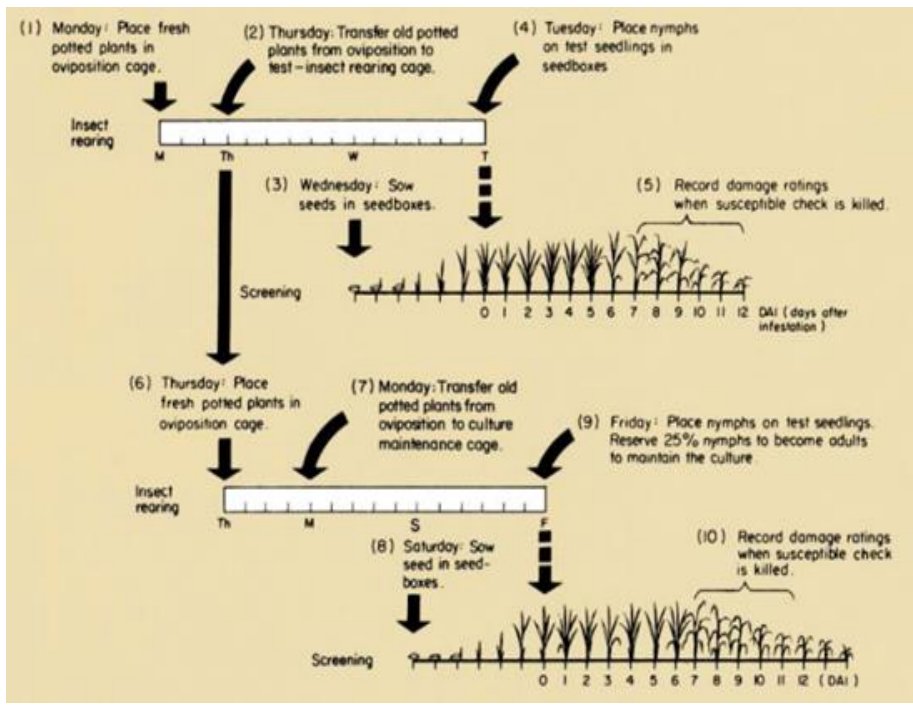

Fig. 2. Sample schedule of sowing seeds and brown planthopper pest investing 7]
TABLE I. GREENHOUSE SCORING GUIDANCE ACCORDING TO 2014 IRRI STANDARD[8]

\begin{tabular}{|c|l|l|}
\hline $\begin{array}{l}\text { Symptom } \\
\text { Score }\end{array}$ & Symptom & Criteria \\
\hline 0 & No injury & $\begin{array}{l}\text { Highly } \\
\text { Resistant }\end{array}$ \\
\hline 1 & Very slight injury & Resistant \\
\hline 3 & $\begin{array}{l}\text { First and 2nd leaves of most plants partially } \\
\text { yellowing }\end{array}$ & $\begin{array}{l}\text { ModerateResist } \\
\text { ant }\end{array}$ \\
\hline 5 & $\begin{array}{l}\text { Pronounced yellowing and stunting or about 10- } \\
\text { 25\% of the plants wilting or dead and remaining } \\
\text { plants severely stuned or dying }\end{array}$ & $\begin{array}{l}\text { Moderate } \\
\text { Susceptible }\end{array}$ \\
\hline 7 & More thanhalfofthe plants wilting or dead & Susceptible \\
\hline 9 & All plants dead & $\begin{array}{l}\text { Highly } \\
\text { Susceptible }\end{array}$ \\
\hline
\end{tabular}

\section{Pre-processing Image}

There were some differences in lighting and contrast at the time the picture was taken. Therefore, enhancement was carried out by performing auto brightness to the picture manually.After that, thresholding was performed between object and the background using the Blue component of RGB color space, as in Figure 3, assuming that $80 \%$ of $\mathrm{B}$ value is the object and the remaining $20 \%$ is the background value. Explanation about the threshold is depicted in Blue screen histogram in Figure 3. On the plant, the frequency was much lower in comparison with the background hence was not shown clearly in the graph.

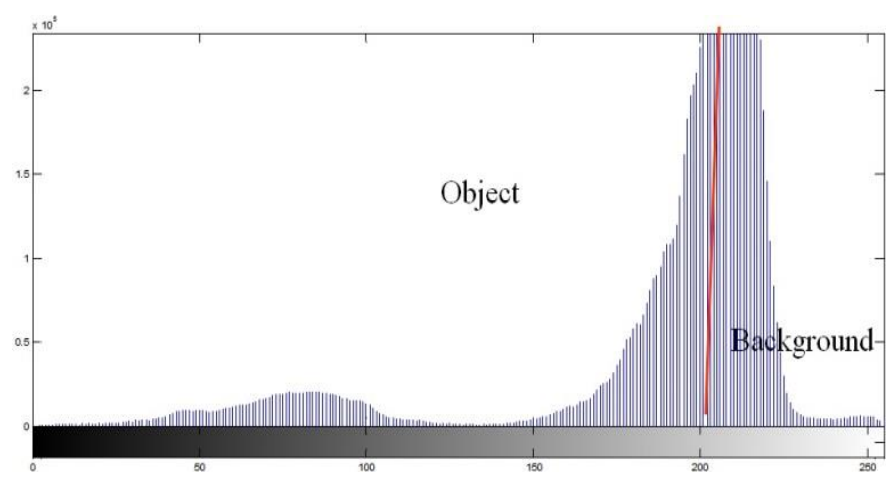

Fig. 3. Sample blue screen histrogram of sample image

\section{Image Color Transform}

In rice plant, sick/ healthy leaf can be different by color. The color component ' $A$ ' from CIELab was used to separate the healthy, sick and dead leaves. The color component ' $A$ ' shows the changing in color from green to red with range of value from 0-255. Healthy plants have more green, whereas sick plants have more yellow to red color components, and dead colors tend to have red to brown colors. Healthy, sick and dead areas may be separated using these color components.

The plant image color space was changed from RGB to CIELab using algorithm [5]. Whereas the formula used was as the following:

$A=1.4749 \times(0.2213 \times R-0.3390 \times G+0.1177 \times B)+128$ 


\section{E. Multilevel Threshold Otsu}

Multilevel Threshold Otsu[9] selects a global threshold value by maximizing the separability of the clusters in ' $A$ ' levels. Assuming that an image can be represented in $L$ ' $\mathrm{A}$ ' levels $(0,1, \ldots, L-1)$. The number of pixels at level $i$ is denoted by $f i$; then, the total number of pixels equals $N=f_{0}+$ $f i+\ldots+f i i_{-}$. For a given ' $\mathrm{A}$ ' level image, the occurrence probability of ' $\mathrm{A}$ ' level $i$ is given by:

$p_{i}=\frac{f_{i}}{N}, \quad p_{i} \geq 0, \quad \sum_{i=0}^{L-1} p_{i}=1$

If an image is segmented into $\mathrm{K}$ clusters $\left(\mathrm{C}_{0}, \mathrm{Ci}, \ldots, \mathrm{C}_{\mathrm{K}-1}\right)$, $\mathrm{K}-1$ thresholds $\left(\mathrm{t}_{0}, \mathrm{t}_{1}, \ldots, \mathrm{t}_{\mathrm{K}-2}\right)$ must be selected. The cumulative probability $\mu_{\mathrm{k}}$ and mean 'A' level for each cluster $\mathrm{C}_{k}$ are respectively given by:

$w_{k}=\sum_{i \in C_{k}} p_{i}$ dan $\mu_{k}=\sum_{i \in C_{k}} i \cdot p_{i} / w_{k}, k \in\{0,1, \ldots, K-1\}$

Therefore, the mean intensity of the whole image $\mu_{k}$ and the between-class variance $\sigma_{\text {B }}^{2}$ are respectively determined by:

$$
\mu_{T}=\sum_{i=0}^{L-1} i \cdot p_{i}=\sum_{k=0}^{K-1} \mu_{k} \cdot \omega_{k}
$$

And

$$
\sigma_{B}^{2}=\sum_{k=0}^{K-1} \omega_{k}\left(\mu_{k}-\mu_{T}\right)^{2}=\sum_{k=0}^{K-1} \omega_{k} \mu^{2}{ }_{k}-\mu^{2}{ }_{T}
$$

Hence, the optimal thresholds $\left(\mathrm{t} *_{0}, \mathrm{t} *_{1}, \ldots, \mathrm{t} *{ }_{\mathrm{K}-2}\right)$ can be determined by maximizing the between-class variance as:

$$
\left\{t_{0}^{*}, t_{1}^{*}, \ldots, t_{K-2}^{*}\right\}=\underset{0 \leq \mathrm{t}_{0}<\ldots<\mathrm{t}_{\mathrm{K}-2}<\mathrm{L}-1}{\arg } \max \left\{\sigma^{2}{ }_{B}\left(t_{0}, t_{1}, \ldots, t_{K-2}\right)\right\}(6)
$$

We used 2 optimal thresholds to separate healthy, sick and dead leave areas.

\section{F. Infected Area Ratio}

After segmentation of healthy, sick and dead leave areas, The number of pixels identified as healthy, sick and dead area were calculated against the total plant areas excluding the background, using the following formula:

$\mathrm{D}=\frac{\mathrm{Pi}}{\mathrm{Pi}+\mathrm{Ps}}$

$\mathrm{D}=$ Damage leaves ratio on seedboxes image

$\mathrm{Pi}=$ The number of infected leave parts on seedboxes image (in pixels)

Ps $=$ The number of healthy leave parts on seedboxes image (in pixels)

Where Damage Area $(\mathrm{Pi})=$ Sick Area + Dead Area

\section{G. Resistance Level Estimation}

Determination of superior varieties resistance level using the proportions of healthy and damage (sick or dead) leave areas and ratio classifications using threshold interval for damage area proportions may be classified into 5 categories, namely score 1 (Resistant), score 3 (Moderate Resistant), score 5 (Moderate Susceptible), score 7 (Susceptible) and score 9 (Highly Susceptible). The severity level may be determined using interval method based on value distribution of infected area proportion [5].

\section{EXPERIMENTAL RESULTS}

\section{A. Data Colected}

Data used were obtained from direct observation when the susceptible check variety (TN1) were dead almost $90 \%$. The data were captured using Macro Digital Camera Canon EOS 550D. The images were captured from seedboxes with white paper background. There were 10 tested varieties and repeated 6 times. 1 control and 5 which were investigated were planthopper.

Based on scoring results, score distributions were not even.

Score $0 \rightarrow 100$ images

Score $1 \rightarrow 20$ images

Score $3 \rightarrow 90$ images

Score $5 \rightarrow 230$ images

Score $7 \rightarrow 100$ images

Score $9 \rightarrow 30$ images

Score 1 or $3 \rightarrow 20$ images

Score 7 or $9 \rightarrow 10$ images

Total: 600 images

Since there were difference of scoring for 30 images, only 570 images were used.

\section{B. Pre-processed Image}

Prior toimage processing, pre-processing must be done to obtain optimum results. Images with white background have higher blue value than plant images, hence may be used to separate background from object (plants). Figure 4 may be used to view the process more clearly.
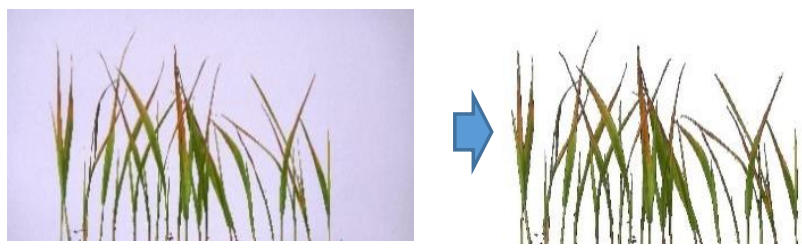

Fig. 4. Background separation from plant objects

Figure 4 shows an illustration of image segmentation with threshold value of $70-90 \%$ from Blue value distribution. The threshold value depends on image quality (contrast/ brightness etc.).

C. Image Extraction

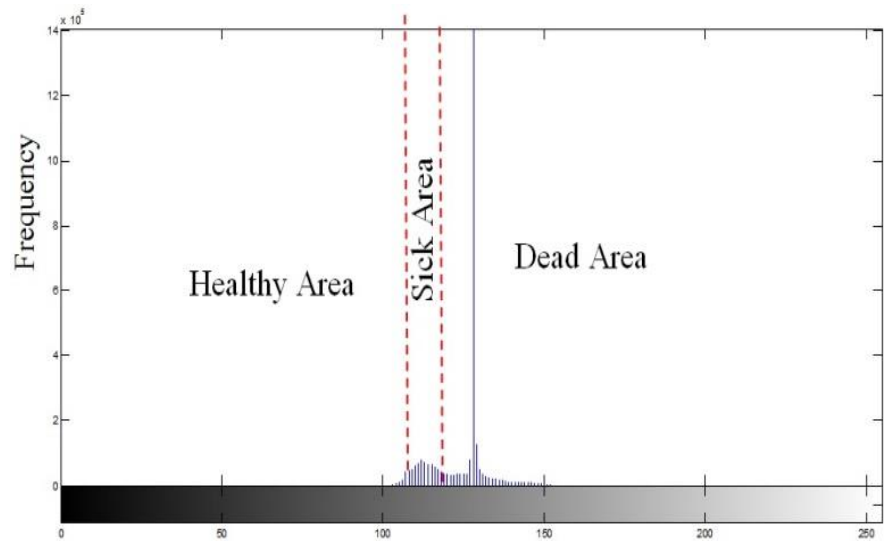

Fig. 5. Sample histogram of A screen from CIELab 
Classification of healthy and sick (yellow to hopperburn) areas was then performed on the processed image. An illustration of image extraction can be seen in Figure 5 and 6.

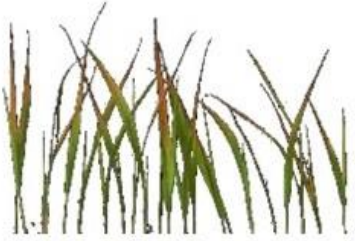
Plant Images
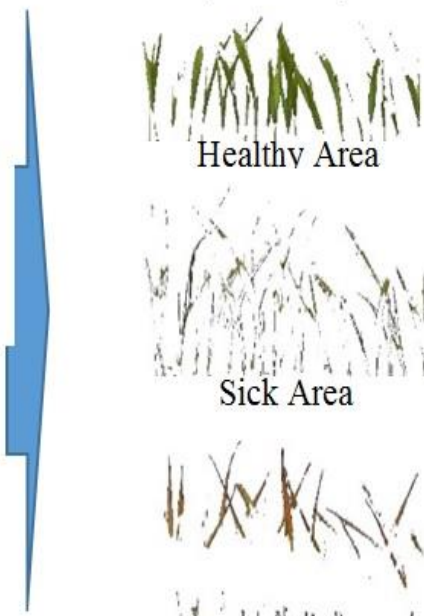

Healthy Area

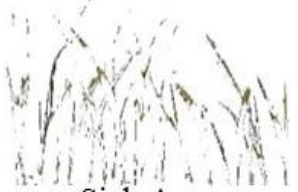

Sick Area

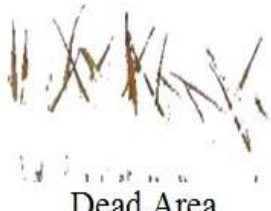

Dead Area
Fig. 6. Separation between healthy, sick and dead area

In this Multilevel Otsu, 16 clusters were used with interval between clusters 16 .

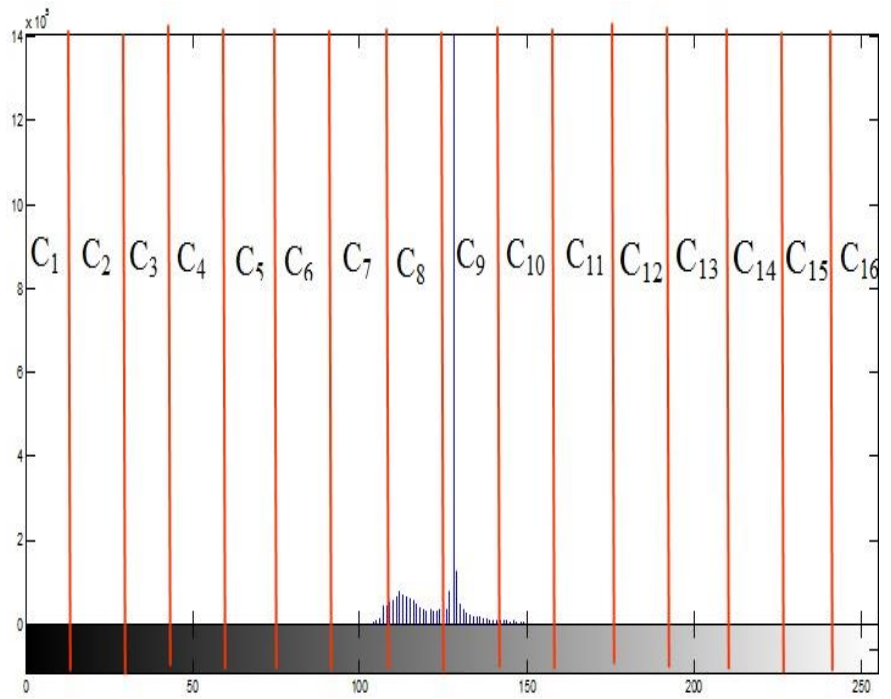

Fig. 7. Sample screen histogram of A divided into16 clusters

Each cluster's $\sigma_{\text {B }}^{2}$ was then calculated. Then 2 clusters with maximum values were chosen from the 16 clusters. For those 2 clusters with maximum $\sigma_{B}^{2}$, the threshold value which satisfy the maximum $\sigma_{B}^{2}$ values between clusters was found. The illustration this process may be seen in Figure 7.

Each image has different threshold, depending on lighting, contrast and A-value distribution. The mean threshold was found in Cluster 8 (112-127) and Cluster 9 (128-143). Whereas the frequency distribution may be seen in Table 2 and Figure 8.

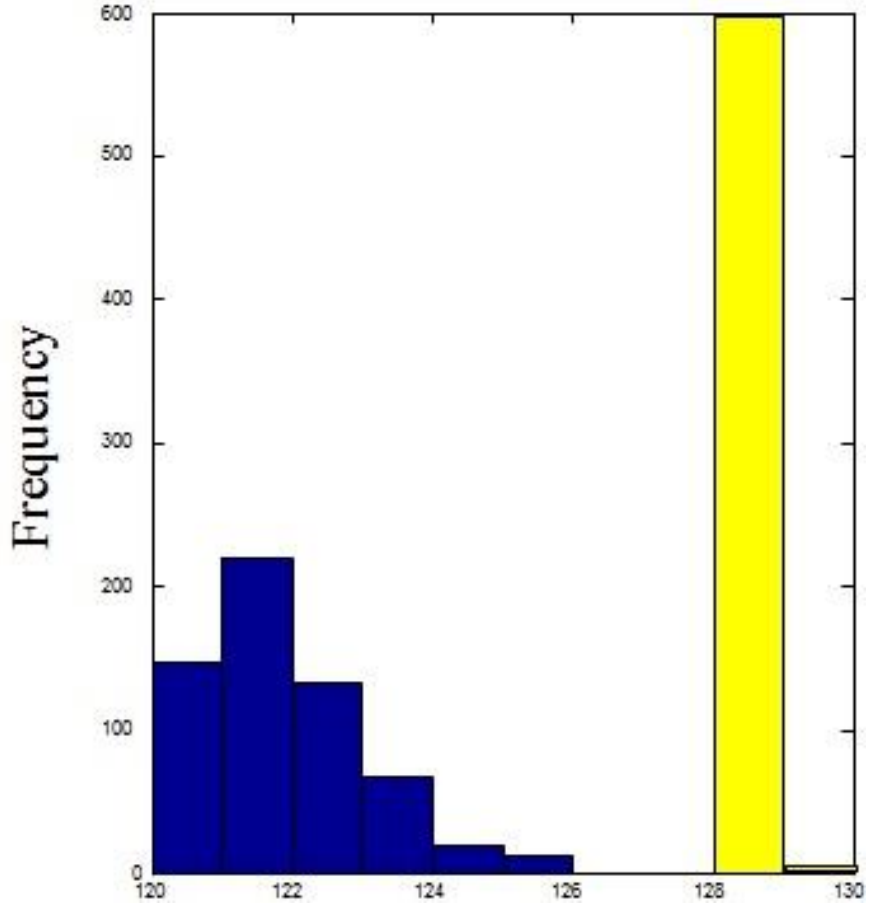

Fig. 8. Frequency Distribution of Threshold Histogram Treshold

\section{Resistance Level Classification}

Number of 570 images were taken from 57 seedboxes varieties which have been infected by brown planthopper pests in this experiment, using seedboxes modification. Three seedboxes was not used, which had different values among experts. From the 570 images used, experts measured that 100 images were classified as score 0 (resistant). Furthermore, 20 images were classified as score 1 (resistant), 90 images as score 3 (Moderate resistant), 230 images as score 5 (Moderate susceptible), 100 images as score 7 (susceptible) and 30 images as score 9 (highly susceptible).

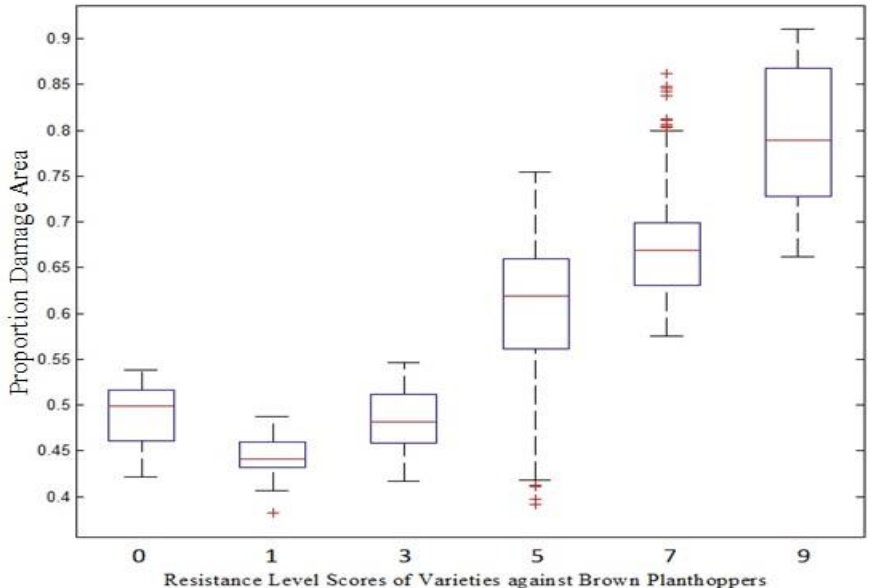

Fig. 9. Boxplotof six resistance levels 
Boxplot on Figure 9 which illustrates data distribution of six resistance level categories shows the distribution of each category. Boxplot for the six classes particularly for score 3 and 5 show quite high classification error. This is due to the overlapping between mean ratio from score 3 and 5. Based on the ratio value distribution of sick area, the resistance scoring rules of paddy against brown planthopper is allowed. The rule is similar to IRRI standard rules, only the number of details is a little different because manual calculation is done per plant in the seedboxes whereas computation uses area approach.

TABLE II. RESISTANCE SCORE RULES BASEd on Ratio Damage AREA

\begin{tabular}{|c|c|}
\hline Resistance Score & Ratio Damage Area (D) $\%$ \\
\hline 0 & $\underline{\mathrm{D}<45}$ \\
\hline 1 & $45<\mathrm{D} \leq 49$ \\
\hline 3 & $49<\mathrm{D} \leq 55$ \\
\hline 5 & $55<\mathrm{D} \leq 65$ \\
\hline 7 & $65<\mathrm{D} \leq 80$ \\
\hline 9 & $\mathrm{D}>80$ \\
\hline
\end{tabular}

\section{E. Classification Result}

All images was scored using the ratio interval damage area in Table 2 and the error rate was calculated as $17.02 \%$. Based on matrix confusion table, it may be seen that classification error happen mainly on the neighborhood classes. The illustration this process may be seen in Table 3 and 4 .

TABLE III. CONFUSION MATRIX FOR IMAGE BASED RESISTANCE SCORING

\begin{tabular}{|c|c|r|r|r|r|r|r|}
\hline \multicolumn{2}{|c|}{} & \multicolumn{7}{|c|}{ Predicted Score } \\
\cline { 2 - 9 } \multicolumn{2}{|c|}{} & 0 & 1 & 3 & 5 & 7 & 9 \\
\hline \multirow{4}{*}{$\begin{array}{c}\text { Actual } \\
\text { Score }\end{array}$} & 0 & 15 & 28 & 57 & & & \\
\cline { 2 - 9 } & 1 & 13 & 7 & & & & \\
\cline { 2 - 9 } & 3 & 18 & 32 & 40 & & & \\
\cline { 2 - 9 } & 5 & 17 & 16 & 22 & 103 & 72 & \\
\cline { 2 - 8 } & 7 & & & & 57 & 32 & 11 \\
\cline { 2 - 8 } & 9 & & & & & 17 & 13 \\
\hline
\end{tabular}

TABLE IV. ERROR RATE CALCULATION, ERROR PROPORTION BASED ON ERROR RATE AND THE FREQUENCY

\begin{tabular}{|c|c|c|}
\hline Error Rate (ER) & Frequency (F) & ER x F \\
\hline 0 & 210 & 0 \\
\hline $1 / 5$ & 252 & 50.4 \\
\hline $2 / 5$ & 91 & 36.4 \\
\hline $3 / 5$ & 17 & 10.2 \\
\hline $4 / 5$ & 0 & 0 \\
\hline $5 / 5$ & 0 & 0 \\
\hline Total & 570 & 97 \\
\hline
\end{tabular}
$\%$

Proportion Error $(\%)=\left(\sum E R \times F\right) / \sum F=97 / 570=17.02$

In this experiment, the error proportion is not too high. Classification error happened on class with close resistance level, for instance class 0 (Highly Resistant), 1 (Resistant) and 3 (Moderate Resistant) also for class 5 (Moderate Susceptible), 7(Susceptible), and 9 (Highly Susceptible).

The following shows image sample for segmentation of healthy, sick and dead areas for each class.

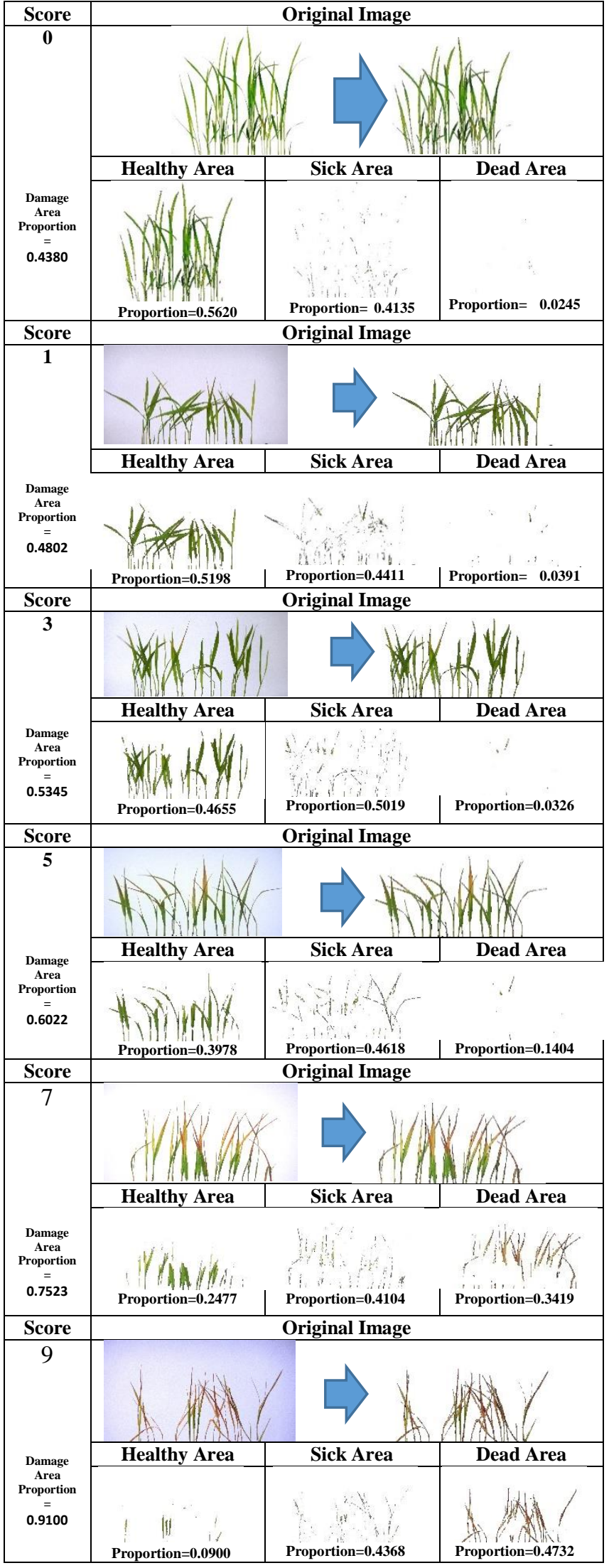

Fig. 10. Sample of Correct Resistance Level Classification 
Figure 10 shows that the higher the score, the larger the infected areas (sick and dead leaves areas). Common mistake usually occur on the neighboring classes. The following is the sample of classification error to the neighboring classes. Figure 11 shows a class 3 was incorrectly classified into class

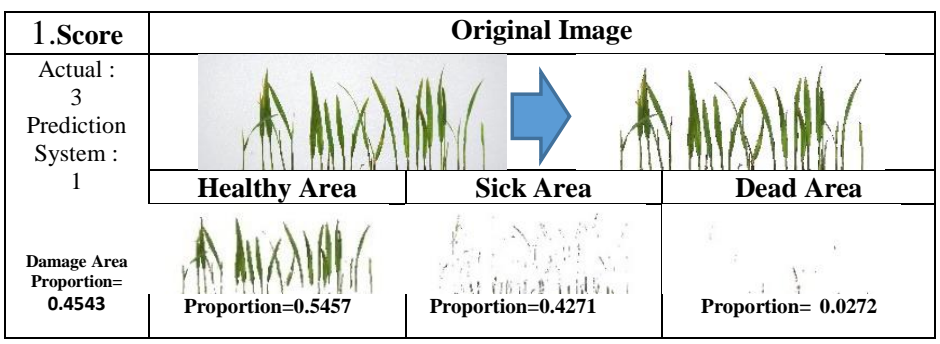

Fig. 11. Sample of incorrect resistance level classification

Quite fatal misclassification in Figure 12 occurred during identification process when the resistance score 5 was recognized as 0 .

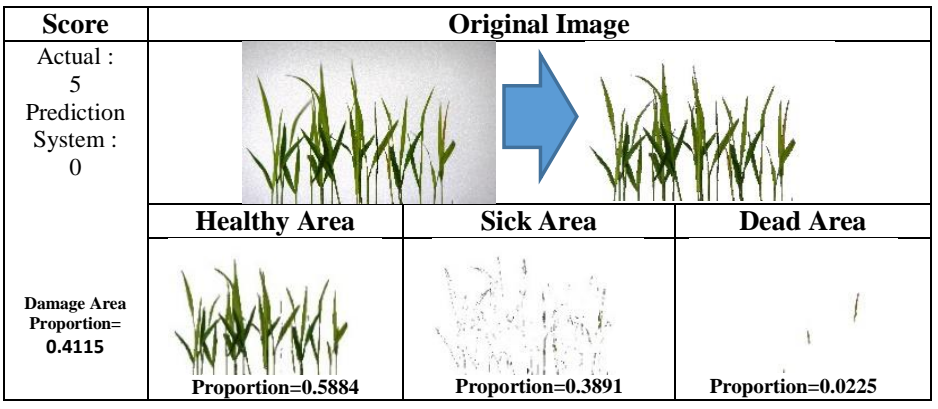

Fig. 12. Sample of incorrect resistance level classification

By only looking for the color feature, it tended to be recognized as score 1 or 3 because the color of the leaf was uniformly green, but the expert gave score 5 . This was because the expert saw some spun leafs. Spun leaf image cannot be detected by the color feature because there were some green colored spun leaves. Classification error occurs because of overlapping in the classification limits of resistance level between adjacent classes. This may also be caused by different lighting level and contrast during image capturing or incomplete pre-processing. Classification error may also happen to manual scoring because quantitatively clear limitation is not yet available to differentiate between resistance level scores.

\section{CONCLUSION AND FUTURE DIRECTION}

In this paper assessing resistance Level of rice varieties using digital image processing are studied. We applied Multilevel Otsu to classify the resistance level by the damaged area ratio. Experimental result shows that all of images were assessed based on the rule and then the model was developed with an error rate of $17.02 \%$. This result show that our proposed method is promising to measure resistance level of rice varieties automatically. Further to this, conditioning such as room lighting is necessary to obtain relatively uniform results of picture capturing to minimize segmentation error. Additionally, it also applies to other features such as shape, height, etc.

\section{ACKNOWLEDGMENT}

The authors would like to express their gratitude to the Directorate General of Higher Educationfor providing Bantuan Operasional Perguruan Tinggi Negeri (BOPTN) to fund this research. We also thankful to the Indonesian Center for Rice Research for giving permission to the authors to perform the research in the Field Biotype Brown Planthopper greenhouse.

\section{REFERENCES}

[1] Du B, Zhang W, Liu BF, Hu J, Wei Z, Shi ZY, He RF, Zhu LL, Chen RZ, Han B, He GC.Identification and characterization of Bph14, a gene conferring resistance to brown planthopper in rice. Proc Natl Acad Sci USA. 2009; $106: 22163-8$.

[2] Sumiati, Ani. 2011. Pengendalian hama wereng batang coklat pada tanaman padi. Jambi (ID): Balai Pengkajian Teknologi Pertanian.

[3] Soemawinata, A. T. dan Soemartono S. 1986. Hama wereng cokelat dan masalah pengendalianya di Indonesia. Di dalam:Prosiding Diskusi Ilmiah Wereng Cokelat dan Pengendalianya. Bogor (ID): Fakultas Pertanian IPB.

[4] Madhogaria S, Schikora M, Koch W, and Cremers D.2011. Pixel-based classification method for detecting unhealthy regions in leaf images.In: 6th IEEE ISIF Workshop on Sensor Data Fusion: Trends, Solutions, Applications (SDF).

[5] Chaudhary P, Chaudhari AK, Cheeran AN, Godara S. 2012. Color transform based approach for disease spot detection on plant leaf. International Journal of Computer Science and Telecommunication. 3(6):65-70.

[6] Asfarian A, Herdiyeni Y, Rauf A, Mutaqin KH. Paddy Diseases Identification with Texture Analysis using Fractal Descriptors Based on Fourier Spectrum.In : International Conference on Computer, Control, Informatics and its Applications (IC3INA) 2013. Jakarta Indonesia

[7] Heinrichs EA, Medrano FG, Rapusas HR.1985. Genetic evaluation for insect resistance in rice. Los Banos (PH): IRRI.

[8] IRRI. 2012. Standard Evaluation System for Rice. Los Banos (PH): IRRI.

[9] Huang DY, Ta Wei Lin, and Wu Chih Hu. 2011. Automatic Multilevel Thresholding Based On Two-Stage Otsu's Method With Cluster Determination By Valley Estimation. In : International Journal of Innovative Computing, Information and Control Volume 7, Number 10, October 2011.

\section{AUTHORS PROFILE}

Elvira Nurfadhilah received her undergraduate degree from Bogor Agricultural University in 2011. She currently works in the Agency for the Assessment and Application of Technology as an Engineering Staff in the Intelligent Computing Lab. She is currently pursuing her Master Degree in Computer Science from Bogor Agricultural University with a research topic on Image Processing.

Yeni Herdiyeni learned a $\mathrm{PhD}$ in Computer Science with the Dissertation on Semantic Image Similarity using Tree from University of Indonesia (2010). Then she conducted Post Doctoral research at Department of Information Science, Graduate School of Science and Engineering, Saga University, Japan, for 5 months (September - January 2012).She had a Master of Computer Science from University of Indonesia with the thesis on 3D Face Recognition (2005). She obtained her first degree in Computer Science from Bogor Agricultural University (IPB), Indonesia (1999). Currently she is conducting research on digital image processing, computer vision and computational intelligence and biodiversity Informatics.

Aunu Rauf is a professor of agricultural entomology at the Bogor Agricultural University-Indonesia. He earned his M.Sc and PhD degrees from University of Wisconsin-Madison, USA in 1980 and 1983, respectively.

Rahmini received $\mathrm{PhD}$ from IPB (Bogor Agricultural University) in 2012 with subject Entomology. She works for Plant Protection Division in Indonesian Center for Rice Research (ICRR) under Indonesian Agency for Agricultural Research and Development (IAARD), Ministry of Agriculture, since 1995 